Article

\title{
Effect of Different Heating Process on the Photoluminescence Properties of Perovskite Eu-Doped $\mathrm{BaZrO}_{3}$ Powder
}

\author{
Kun-Neng Chen ${ }^{1}$, Chao-Ming Hsu ${ }^{2}$, Jing Liu ${ }^{3}$, Yi-Tang Chiu ${ }^{4}$ and Cheng-Fu Yang ${ }^{4, *}$
}

Received: 31 October 2015; Accepted: 7 January 2016; Published: 18 January 2016

Academic Editors: Sheng-Yuan Chu and Takayoshi Kobayashi

1 Department of Electrical Engineering, Kun-Shan University, No.195, Kunda Rd., Yongkang Dist., Tainan 710, Taiwan; knchen@mail.ksu.edu.tw

2 Department of Mechanical Engineering, National Kaohsiung University of Applied Science, No. 415 Chien Kung Road, Kaohsiung 807, Taiwan; jammy@kuas.edu.tw

3 School of Information Engineering, Jimei University, Xiamen 361021, China; jingliu@jmu.edu.cn

4 Department of Chemical and Materials Engineering, National University of Kaohsiung, No. 700 Kaohsiung University Road, Nan-Tzu District, Kaohsiung 811, Taiwan; b0933563387@hotmail.com

* Correspondence: cfyang@nuk.edu.tw; Tel.: +886-7-5919283; Fax: +886-7-5919277

\begin{abstract}
In this study, $\mathrm{BaZrO}_{3}: \mathrm{Eu}_{0.025}$ powder was synthesized through the solid-state reaction method with two different heating processes. For the one-step process, the $\mathrm{BaZrO}_{3}: \mathrm{Eu}_{0.025}$ powder was heated to $1000{ }^{\circ} \mathrm{C}-1400{ }^{\circ} \mathrm{C}$ for $2 \mathrm{~h}$. For the two-step heating process, the $\mathrm{BaZrO}_{3}: \mathrm{Eu}_{0.025}$ powder was pre-heated at $800{ }^{\circ} \mathrm{C}$ for $2 \mathrm{~h}$, after being cooled to room temperature and ground, then the powder was heated to $1000{ }^{\circ} \mathrm{C}-1400{ }^{\circ} \mathrm{C}$ again for $2 \mathrm{~h}$. The optimum excitation optical wavelength of $\mathrm{BaZrO}_{3}: \mathrm{Eu}_{0.025}$ powders were $271 \mathrm{~nm}$ and the maximum intensity of the emission spectrum of $\mathrm{BaZrO}_{3}: \mathrm{Eu}_{0.025}$ powders increased with increasing heating temperature. The all-heated $\mathrm{BaZrO}_{3}: \mathrm{Eu}_{0.025}$ powders showed two strong orange emission bands peaking at the wavelengths of 574 and $596 \mathrm{~nm}$ and two weak emission bands peaking at 620 and $650 \mathrm{~nm}$. As the heating temperatures were $1300{ }^{\circ} \mathrm{C}$ and $1400{ }^{\circ} \mathrm{C}$, the maximum intensity of one-step heating $\mathrm{BaZrO}_{3}: \mathrm{Eu}_{0.025}$ powders appeared at the ${ }^{5} \mathrm{D}_{0}-{ }^{7} \mathrm{~F}_{0}(574 \mathrm{~nm})$ and the maximum intensity of one-step heating $\mathrm{BaZrO}_{3}: \mathrm{Eu}_{0.025}$ powders appeared at the ${ }^{5} \mathrm{D}_{0}-{ }^{7} \mathrm{~F}_{1}(596 \mathrm{~nm})$ transitions of $\mathrm{Eu}^{3+}$ ions, respectively.
\end{abstract}

Keywords: $\mathrm{BaZrO}_{3}$ phosphor; Different heating processes; Europium; Photoluminescence property

\section{Introduction}

Inorganic oxide luminescence materials have practical applications in many different devices for artificial light production. For example, a red phosphor is helpful to generate white light LEDs under the excitation of blue or near-UV (NUV) LEDs. The dopant europium $\left(\mathrm{Eu}^{2+}\right.$ or $\left.\mathrm{Eu}^{3+}\right)$ ions exhibit very interesting photoluminescence properties in different oxidation states. The $\mathrm{Eu}^{2+}$ ion shows a $5 \mathrm{~d}-4 \mathrm{f}$ transition, and this transition can cause the phosphors to vary from ultraviolet to yellow emissions. Europium in the trivalent $\left(\mathrm{Eu}^{3+}\right)$ state gives red $\left({ }^{5} \mathrm{D}_{0} \rightarrow{ }^{7} \mathrm{~F}_{2}\right.$ transition) or reddish-orange emissions $\left({ }^{5} \mathrm{D}_{0} \rightarrow{ }^{7} \mathrm{~F}_{1}\right.$ transition) as reported in different $\mathrm{Eu}^{3+}$-doped oxides, for example in host borates [1] and tungstates [2], respectively. Xia et al. had reported that as the multiplex compound of halides and borates of the $\mathrm{Ca}_{2} \mathrm{BO}_{3} \mathrm{Cl}: \mathrm{Eu}^{2+}$ composition is synthesized by the solution combustion method, this composition emits blue and yellow emissions to form a bright yellow emission [3]. Xia et al. also found that the novel $\mathrm{Ca}_{2} \mathrm{~B}_{5} \mathrm{O}_{9} \mathrm{Br}: \mathrm{Eu}^{2+}$ phosphor would have a blue emission when it was prepared by the microwave method, and the novel $\mathrm{Ca}_{2} \mathrm{~B}_{5} \mathrm{O}_{9} \mathrm{Br} \mathrm{Eu}^{2+}$ phosphor had been proved to be the promising phosphor for white light-emitting diodes [4]. Eu-doped oxide phosphors have also been intensively 
studied due to their intense sharp red emission centered at around $611 \mathrm{~nm}$, which is emits a red color and is one of the three primary colors. For example, Murthy et al. found that $\mathrm{YGdBO}_{3}$ doped with Eu would generate emissions at $367,454,595,611$, and $628 \mathrm{~nm}$, and the intensity of peak at $366 \mathrm{~nm}$ is relatively less as compared to 594, 613 and $629 \mathrm{~nm}$ peaks [5].

Alkaline earth zirconates can be used to form the compounds with the general formula $A^{2+} B^{4+} \mathrm{O}_{3}$ (where $A=\mathrm{Ca}, \mathrm{Pb}, \mathrm{Sr}, \mathrm{Ba} ; B=\mathrm{Ti}, \mathrm{Zr}$ ) having perovskite-type structure. Recently, more and more research has been focused on the luminescent properties of rare earth ion-doped $A B \mathrm{O}_{3}$ perovskite-based oxides, because perovskite-based phosphors are very stable and they can steadily work in various environments, and that is a merit for the phosphors' application. In the formula of $A^{2+} B^{4+} \mathrm{O}_{3}$ compositions, $\mathrm{BaZrO}_{3}$ ceramic has a perovskite structure and it can be doped easily by divalent or trivalent rare earth ions; it also possesses many good properties such as high refractive index, wide energy band gap, low optical loss, chemical and photo-chemical stability and excellent mechanical, electrical, thermal and optical properties, and perfect single-phase structure [6,7]. Different rare earth-doped $\mathrm{BaZrO}_{3}$ powders can be applied as a new class of luminescence materials. $\mathrm{BaZrO}_{3}$-based powders are known for their outstanding properties such as high thermal and chemical stability and easily forming the single crystalline phase by using the solid-state reaction method. $\mathrm{Eu}^{3+}$-doped $\mathrm{BaZrO}_{3}$ phosphors also show the merits of brightness and flexible industrial processing ability, and they are suitable for lighting and display devices. As such, more and more investigations are focused on luminescent properties and mechanisms of rare earth ion-doped $\mathrm{BaZrO}_{3}$ [8], in which $\mathrm{Yb}^{3+}[9]$, $\mathrm{Tm}^{3+}[9], \mathrm{Eu}^{3+}[10,11], \mathrm{Ti}^{+4}$ [11], and $\mathrm{Tb}^{3+}$ [12] have been developed as dopants in $\mathrm{BaZrO}_{3}$ powder, and their luminescent properties and corresponding mechanisms were discussed.

Yang et al. found that $\beta$-SiAlON:Eu phosphor powders exhibit a typical rod-like morphology. The low $\mathrm{Eu}^{2+}$ concentrations would cause the $\beta$-SiAlON:Eu phosphors to have a blue emission and the high $\mathrm{Eu}^{2+}$-doping concentrations would cause the $\beta$-SiAlON:Eu phosphors to have a green emission [13]. Zambare and Murthy adopted a standard solid-state reaction method to investigate the properties of Eu-doped $\mathrm{YPVO}_{4}, \mathrm{Y}_{2} \mathrm{O}_{3}$, and $\mathrm{YLaVO}_{4}$ phosphors [14]. They used a $254 \mathrm{~nm}$ wavelength to excite the photoluminescence emission spectra of $\mathrm{YPVO}_{4}: \mathrm{Eu}^{3+}(0.5 \%)$ and $\mathrm{Y}_{2} \mathrm{O}_{3}: \mathrm{Eu}^{3+}(0.5 \%)$, and $\mathrm{Y}(\mathrm{PV}) \mathrm{O}_{4}: \mathrm{Eu}^{3+}$ displayed photoluminescence (PL) emissions at 365, 540, 561, 594, and $611 \mathrm{~nm}$, and $\mathrm{Y}_{2} \mathrm{O}_{3}: \mathrm{Eu}^{3+}$ displayed PL emissions at 536, 583, 589, 594, 600, 615, and $632 \mathrm{~nm}$, respectively. They used a $450 \mathrm{~nm}$ wavelength to excite the $\mathrm{Y}_{0.5} \mathrm{LaVO}_{4}: \mathrm{Eu}(0.5 \%)$ phosphor and it generated a strong and broad emission in the UV region of 240 to $300 \mathrm{~nm}$ [14]. Jang et al. found that $\mathrm{Eu}^{2+}$-doped $\alpha$-sialon phosphor exhibited wide absorption in ultraviolet (UV) and visible range, and a high broad emission band peaking at from 570 to $582 \mathrm{~nm}$ [15].

$\mathrm{Yu}$ et al. investigated the $\mathrm{Eu}^{3+}$-doped double-perovskite $\mathrm{LiBaLa}\left[\mathrm{TeO}_{6}\right], \mathrm{NaBaLa}\left[\mathrm{TeO}_{6}\right]$, and $\mathrm{LiBaBi}\left[\mathrm{TeO}_{6}\right]$ compositions as phosphors. They found that those double-perovskite powders show the dominated electric dipole transition ${ }^{5} \mathrm{D}_{0} \rightarrow{ }^{7} \mathrm{~F}_{2}$ with a pure red luminescence color and a fast decay. They also found that $\mathrm{Eu}^{3+}$-doped $\mathrm{NaCaBi}\left[\mathrm{TeO}_{6}\right]$ presents the dominant reddish-orange emission from the magnetic dipole transition ${ }^{5} \mathrm{D}_{0} \rightarrow{ }^{7} \mathrm{~F}_{1}$ and a longer luminescence lifetime [16]. In the past, Kanie et al. synthesized Eu-doped $\mathrm{BaZrO}_{3}$ fine particles with high crystallinity by using hydrothermal reactions and they also investigated the effect of size and shape on the fluorescence properties of Eu-doped $\mathrm{BaZrO}_{3}$ for its use as a phosphor [17]. The $\mathrm{Eu}^{3+}$-doped orthorhombic $\mathrm{BaZrO}_{3}$ (Eu-BZO) powders could be synthesized by the traditional one-step high temperature solid-state reaction method [11]. In the past, we had found that different heating and fabrication processes will have a large effect on the properties of prepared ceramics. For example, we prepared the $0.95\left(\mathrm{Na}_{0.5} \mathrm{Bi}_{0.5}\right) \mathrm{TiO}_{3}-0.05$ $\mathrm{BaTiO}_{3}$ ceramics with different heating processes and we found that the heating process had a large effect on their crystalline and electrical properties [18]. Nevertheless, no research has focused on the effect of different heating processes on the luminescent properties of $\mathrm{BaZrO}_{3}$ powders. Thus, in this study, we investigated two different heating processes to synthesize the Eu-BZO powders by the traditional solid-state reaction method. The first was the one-step solid-state reaction method, where the Eu-BZO powders were directly heated to $1100^{\circ} \mathrm{C}-1400{ }^{\circ} \mathrm{C}$. The second was the two-step 
solid-state reaction method, where the Eu-BZO powders were pre-heated at $800{ }^{\circ} \mathrm{C}$ and then heated to $1100{ }^{\circ} \mathrm{C}-1400{ }^{\circ} \mathrm{C}$ after cooling. After the different heating processes, the optical properties of $\mathrm{BaZrO}_{3}$ powders as a function of different heating temperatures were presented. The heated $\mathrm{BaZrO}_{3}$ powders showed two strong orange emission bands peaking at the wavelengths of 574 and $596 \mathrm{~nm}$ and two weak emission bands peaking at around 620 and $650 \mathrm{~nm}$ under the excitation optimum optical wavelength of $271 \mathrm{~nm}$. We found that the heating process would have a large effect on the properties of the emission spectrum of Eu-BZO powders and we would investigate the luminescent properties of $\mathrm{BaZrO}_{3}$ powders under different heating processes in detail.

\section{Experimental Section}

$\mathrm{BaZrO}_{3}: \mathrm{Eu}_{0.025}$ powder was synthesized through the solid-state reaction method. $\mathrm{BaCO}_{3}, \mathrm{ZrO}_{2}$, and $\mathrm{Eu}_{2} \mathrm{O}_{3}$ powders (Admat Midas Inc, Norristown, PA, USA) were weighed according to the composition formula $\mathrm{BaCO}_{3}+\mathrm{ZrO}_{2}+0.0125 \mathrm{Eu}_{2} \mathrm{O}_{3}$ (Eu-BZO). After being mixed in acetone, dried, and ground, two different heating processes were used to heat the Eu-BZO composition in an air atmosphere. According to the stoichiometry, the reactants were heated at two different processes. For the first process, the Eu-BZO powder was heated to $1000{ }^{\circ} \mathrm{C}-1400{ }^{\circ} \mathrm{C}$ for $2 \mathrm{~h}$, which were abbreviated one-step Eu-BZO powders. The second two-step heating process was used. The Eu-BZO powder was pre-heated at $800^{\circ} \mathrm{C}$ for $4 \mathrm{~h}$, after being cooled to room temperature and ground, the powder was heated to $1100{ }^{\circ} \mathrm{C}-1400{ }^{\circ} \mathrm{C}$ again for $2 \mathrm{~h}$, which were abbreviated two-step Eu-BZO powders. Morphology variations of Eu-BZO powders were measured using a field emission scanning electron microscopy (FESEM), and their crystalline structures were measured using X-ray diffraction (XRD) patterns with $\mathrm{Cu} \mathrm{K} \alpha$ radiation $(\lambda=1.5418 \AA$ ). PL properties were recorded at room temperature in the wavelength range of 450-800 nm on a Hitachi F-4500 fluorescence spectrophotometer (Hitachi, Tokyo, Japan). Liu and Wang had excited the $\mathrm{BaZr}_{1-x} \mathrm{Eu}_{x} \mathrm{O}_{3}$ powders $\left(\mathrm{BaZrO}_{3}\right.$ doped with $\left.\mathrm{Eu}^{3+}\right)$ with $\lambda_{\mathrm{em}}=597 \mathrm{~nm}$ and $258 \mathrm{~nm}$, and they found the $258 \mathrm{~nm}$ had the better excitation effect on the $\mathrm{BaZr}_{1-x} \mathrm{Eu}_{\mathrm{x}} \mathrm{O}_{3}$ powders. This result suggests that we would need to find the optimum optical wavelength for exciting the Eu-BZO powders. In this study, the three-dimensional (3D)-scanning process by using spectrophotometer was used to find the optimum optical wavelength and this value was dependent on the phosphors' compositions and preparing process. We had found that for all Eu-BZO powders the optimum value was $271 \mathrm{~nm}$ and the Eu-BZO powders excited by other wavelengths had the weaker PL intensities.

\section{Results and Discussion}

FESEM (JEOL JSM-6700, Tokyo, Japan) was used to examine the morphology of the heated $\mathrm{Eu}-\mathrm{BZO}$ powders as a function of heating process and heating temperature. Figure 1 shows the FESEM images of Eu-BZO powders as a function of heating process and heating temperature, which indicates that as the heating process was changed, the surface morphologies apparently changed as well. As the heating temperature was $1100^{\circ} \mathrm{C}$, as Figure $1 \mathrm{a}$,c show that the morphologies of the one-step and two-step heated Eu-BZO powders exhibited nanoparticle assembled matrixes. Surface morphologies of the $1200^{\circ} \mathrm{C}$-heated Eu-BZO powders also showed the nano-particle structure particles, and they had a similar result to those of the $1100{ }^{\circ} \mathrm{C}$-heated Eu-BZO powders as well as large particle sizes (not shown here). As heating temperature was raised to $1300^{\circ} \mathrm{C}$, as Figure $1 \mathrm{~b}$, d show, the morphologies of the Eu-BZO powders exhibited large-particle assembled matrixes. As the heating temperature was raised to $1400^{\circ} \mathrm{C}$, the morphologies of the Eu-BZO powders also exhibited large-particle assembled matrixes (not shown here). 

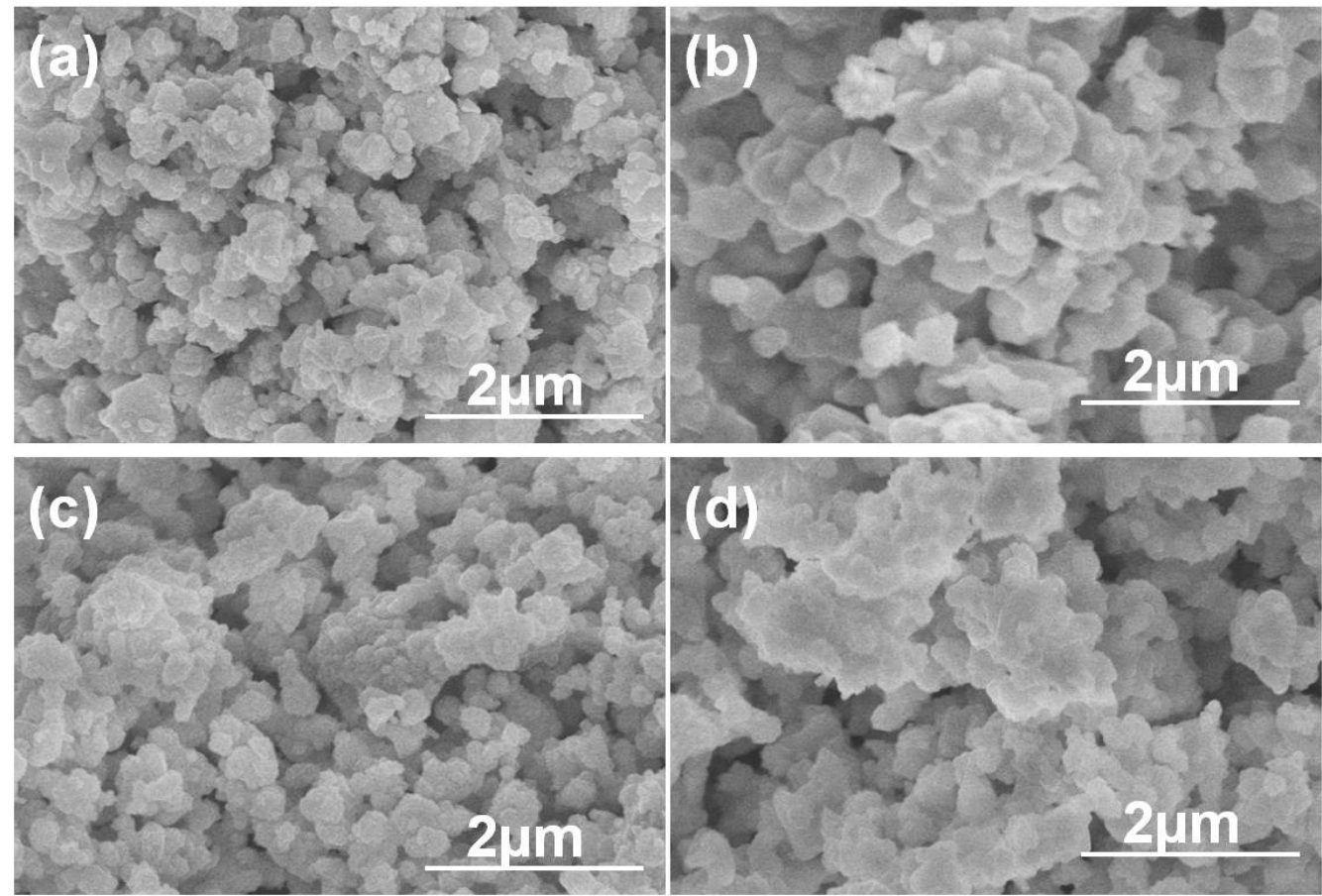

Figure 1. Morphology of $\mathrm{BaZrO}_{3}: \mathrm{Eu}_{0.025}$ powders as a function of heating process and heating temperature. One-step Eu-BZO powder calcined at (a) $1100{ }^{\circ} \mathrm{C}$ and (b) $1300{ }^{\circ} \mathrm{C}$, and two-step Eu-BZO powder calcined at (c) $1100{ }^{\circ} \mathrm{C}$ and (d) $1300{ }^{\circ} \mathrm{C}$, respectively.

As the same heating temperature was used, the two-step heated Eu-BZO powders aggregated together to form larger particle sizes than one-step heated powders did. Although the one-step and two-step heated Eu-BZO powders had different surface morphologies, they were a cluster of crystallines as confirmed by XRD in Figure 2. Therefore, all heated Eu-BZO powders, regardless of heating process and heating temperature, showed stable cubic perovskite features. In order to achieve high photoluminescence properties, the preparation of Eu-BZO powders forming the cubic perovskite phase is very important because the crystallization of the Eu-BZO powders will influence their photoluminescence properties.

As Figure 2a shows, the $2 \theta$ value of the (002) diffraction peak was shifted from 30.18 to 30.14 as the heating temperature increased from $1100{ }^{\circ} \mathrm{C}$ to $1400^{\circ} \mathrm{C}$. The full width at half maximum (FWHM) values for the (110) diffraction peak of the one-step Eu-BZO powder were 0.36, 0.27, 0.22, and 0.19, as the heating temperature was $1100{ }^{\circ} \mathrm{C}, 1200^{\circ} \mathrm{C}, 1300^{\circ} \mathrm{C}$, and $1400^{\circ} \mathrm{C}$; as Figure $2 \mathrm{~b}$ shows, the $2 \theta$ value of the (110) diffraction peak was located at 30.18 as the heating temperature increased from $1100{ }^{\circ} \mathrm{C}$ to $1400{ }^{\circ} \mathrm{C}$. The FWHM values for the (110) peak of the two-step Eu-BZO powder were 0.26, 0.25, 0.19, and 0.17 , as the heating temperature at the second process was $1100^{\circ} \mathrm{C}, 1200^{\circ} \mathrm{C}, 1300^{\circ} \mathrm{C}$, and $1400{ }^{\circ} \mathrm{C}$, respectively. As the same heating temperature was used, the diffraction intensity of the two-step Eu-BZO powders was higher than that of the one-step Eu-BZO powders and the FWHM value of the two-step Eu-BZO powders was smaller than that of the one-step Eu-BZO powder. These results suggest that as the same heating temperatures is used, the crystallization of the two-step Eu-BZO powders is better than that of the one-step Eu-BZO powders. 

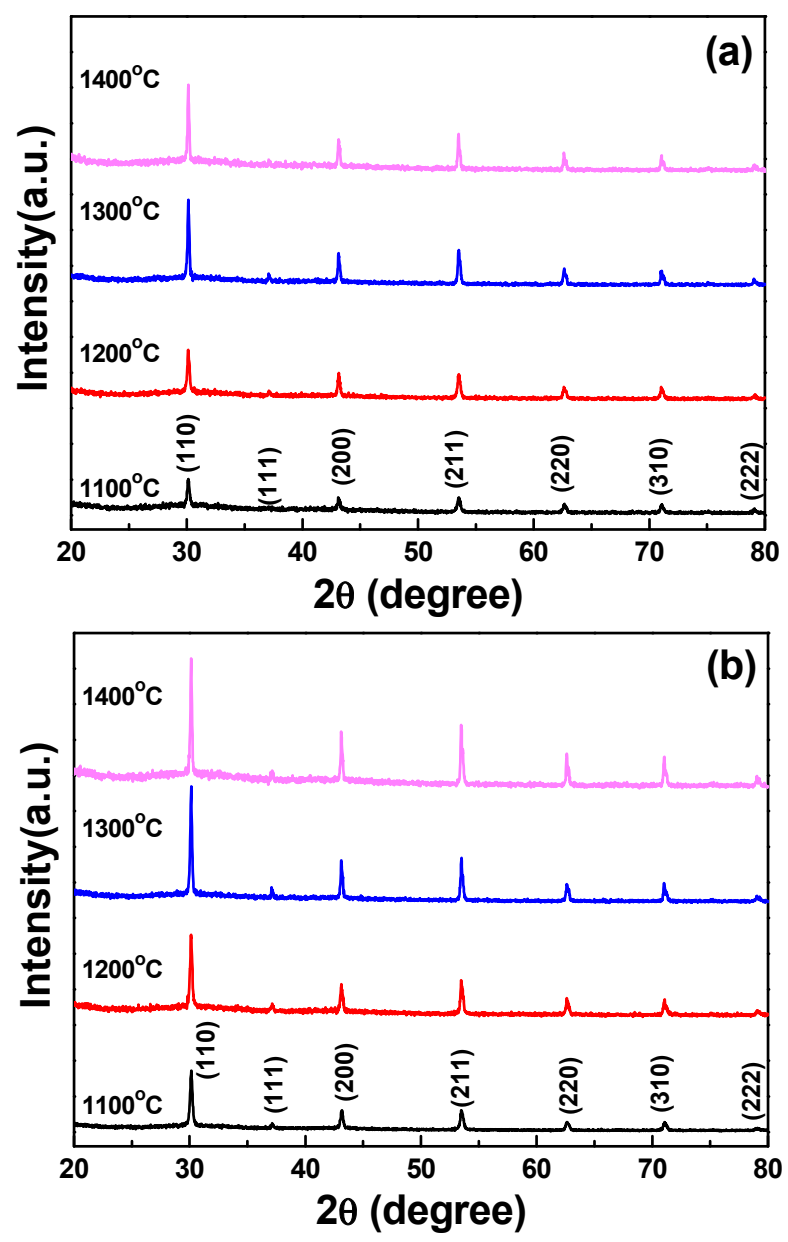

Figure 2. X-ray diffraction (XRD) patterns of $\mathrm{BaZrO}_{3}: \mathrm{Eu}_{0.025}$ powders as a function of heating process and heating temperature. (a) One-step Eu-BZO powder and (b) Two-step Eu-BZO powder, respectively.

For the two-step and one-step Eu-BZO powders, the diffraction intensity increased and the FWHM value decreased with the increasing heating temperature. Those results also suggest that Eu-BZO powder calcined at higher temperatures has a better crystalline structure and the pre-heating temperature and calcining temperature are the two important parameters influencing the crystalline structure of the Eu-BZO powders. Concerning the structural aspect, the $\mathrm{BaZrO}_{3}$ compound shows a cubic perovskite-type crystal structure and its space group (Pm3m:221) contains 48 symmetry operations including inversion. The lattice constant $a$ in the present report was calculated by using the $2 \theta$ value. The presented Eu-BZO powders exhibit cubic geometry having $a=0.41923 \mathrm{~nm}$, which is in good agreement with Joint Committee on Powder Diffraction Standards (JCPDS) file No. 89-2486. The radii of $\mathrm{Zr}^{4+}, \mathrm{Ba}^{2+}$, and $\mathrm{Eu}^{3+}$ are $0.72 \AA, 1.35 \AA$, and $0.947 \AA$, respectively. Due to the difference in the ion sizes between $\mathrm{Ba}^{2+}$ and $\mathrm{Zr}^{4+}$, the $\mathrm{Eu}^{3+}$ ions are expected to be substituted for the $\mathrm{Zr}^{4+}$ sites in the $\mathrm{BaZrO}_{3}$ lattice. Kanie et al. had used the hydrothermal synthesis method to prepare the Eu-doped $\mathrm{BaZrO}_{3}$ powders and they changed the amount of $\mathrm{Eu}^{3+}$ ions from 2.0 to $8.0 \mathrm{~mol}$. \% based on the $\mathrm{Zr}^{4+}$ ions [17]. The $2 \theta$ value of the (110) diffraction peak of undoped BZO powders is located at 30.21 with $a=0.41915 \mathrm{~nm}$ (not shown here). If the $\mathrm{Eu}^{3+}$ ions are substituted for the $\mathrm{Ba}^{2+}$ sites, the lattice in the $\mathrm{BaZrO}_{3}$ will decrease and the $2 \theta$ value of the (110) diffraction peak will be shifted to a larger value. The $2 \theta$ value of the (110) diffraction peak of the Eu-BZO powders was located at 30.18 with $a=0.41923 \mathrm{~nm}$, which is longer than that of the undoped-BZO powders. This result suggests that $\mathrm{Eu}^{3+}$ ions are substituted for the $\mathrm{Zr}^{4+}$ sites and the lattice in the $\mathrm{BaZrO}_{3}$ increases and the $2 \theta$ value of the (110) diffraction peak will be shifted to a smaller value. Nevertheless, we used the solid-state 
reaction to prepare the $0.0125 \mathrm{Eu}_{2} \mathrm{O}_{3}$-doped $\mathrm{BaZrO}_{3}$, and we believe that the all $\mathrm{Eu}^{3+}$ ions will occupy the $\mathrm{Zr}^{4+}$ sites.

The PL emission spectra of Eu-BZO powders excited at a wavelength of $271 \mathrm{~nm}$ are shown in Figures 3 and 4 for the light wavelength range of 450-800 nm and 550-700 nm, respectively. For the one-step and the two-step Eu-BZO powders, four emission peaks were revealed in the spectra. In the past, the spectra of $\mathrm{BaZr}_{1-x} \mathrm{Eu}_{x} \mathrm{O}_{3}\left(\mathrm{BaZrO}_{3}\right.$ doped with $\left.\mathrm{Eu}^{3+}\right)$ powders consisted of a series of resolved emission peaks at 574, 596, 616, 623, 651, 673, 696 and $704 \mathrm{~nm}$, which can be assigned to ${ }^{5} \mathrm{D}_{0}{ }^{-}{ }^{7} \mathrm{~F}_{\mathrm{J}}(J=0,1,2,3,4)$ transitions of Eu ${ }^{3+}$ ions, namely, ${ }^{5} \mathrm{D}_{0}-{ }^{7} \mathrm{~F}_{0}(576 \mathrm{~nm}),{ }^{5} \mathrm{D}_{0}-{ }^{7} \mathrm{~F}_{1}(597 \mathrm{~nm}),{ }^{5} \mathrm{D}_{0}-{ }^{7} \mathrm{~F}_{2}$ $(616,623 \mathrm{~nm}),{ }^{5} \mathrm{D}_{0}{ }^{7} \mathrm{~F}_{3}(651 \mathrm{~nm})$, and ${ }^{5} \mathrm{D}_{0}-{ }^{7} \mathrm{~F}_{4}(673,696$ and $704 \mathrm{~nm})$, respectively [19]. Liu and Wang's research results also showed that the emission intensities of ${ }^{5} \mathrm{D}_{0}-{ }^{7} \mathrm{~F}_{0}(576 \mathrm{~nm}),{ }^{5} \mathrm{D}_{0}-{ }^{7} \mathrm{~F}_{1}(597 \mathrm{~nm})$, and ${ }^{5} \mathrm{D}_{0}{ }^{7} \mathrm{~F}_{2}(616,623 \mathrm{~nm})$ almost had the same values, even if the Eu concentration in the $\mathrm{BaZr}_{1-x} \mathrm{Eu}_{\mathrm{x}} \mathrm{O}_{3}$ phosphor powders was different [19].

In this study, we had different results as compared with Liu and Wang's research results. As Figures 3 and 4 show, the heated $\mathrm{BaZrO}_{3}$ powders had two strong orange emission bands peaking at the wavelengths of 574 and $596 \mathrm{~nm}$ and two weak emission bands peaking at 620 and $650 \mathrm{~nm}$ under the optimum excitation optical wavelength of $271 \mathrm{~nm}$. The emission spectrum consisted of sharp peaks of two strong bands at 574 and $596 \mathrm{~nm}$ corresponding to the ${ }^{5} \mathrm{D}_{0}-{ }^{7} \mathrm{~F}_{0}(574 \mathrm{~nm})$ and ${ }^{5} \mathrm{D}_{0}-{ }^{7} \mathrm{~F}_{1}(596 \mathrm{~nm})$ transitions of $\mathrm{Eu}^{3+}$ ions, and of two weak bands at 620 and $650 \mathrm{~nm}$ corresponding to the ${ }^{5} \mathrm{D}_{0}-{ }^{7} \mathrm{~F}_{2}$ $(620 \mathrm{~nm})$ and ${ }^{5} \mathrm{D}_{0}{ }^{-} \mathrm{F}_{3}(650 \mathrm{~nm})$ transitions of $\mathrm{Eu}^{3+}$ ions, respectively. The maximum emission intensity, which will occur dependent on the heating process and heating temperature, will be observed at $574 \mathrm{~nm}$ or $596 \mathrm{~nm}$ due to the ${ }^{5} \mathrm{D}_{0} \rightarrow{ }^{7} \mathrm{~F}_{0}$ or ${ }^{5} \mathrm{D}_{0} \rightarrow{ }^{7} \mathrm{~F}_{1}$ transitions of $\mathrm{Eu}^{3+}$.
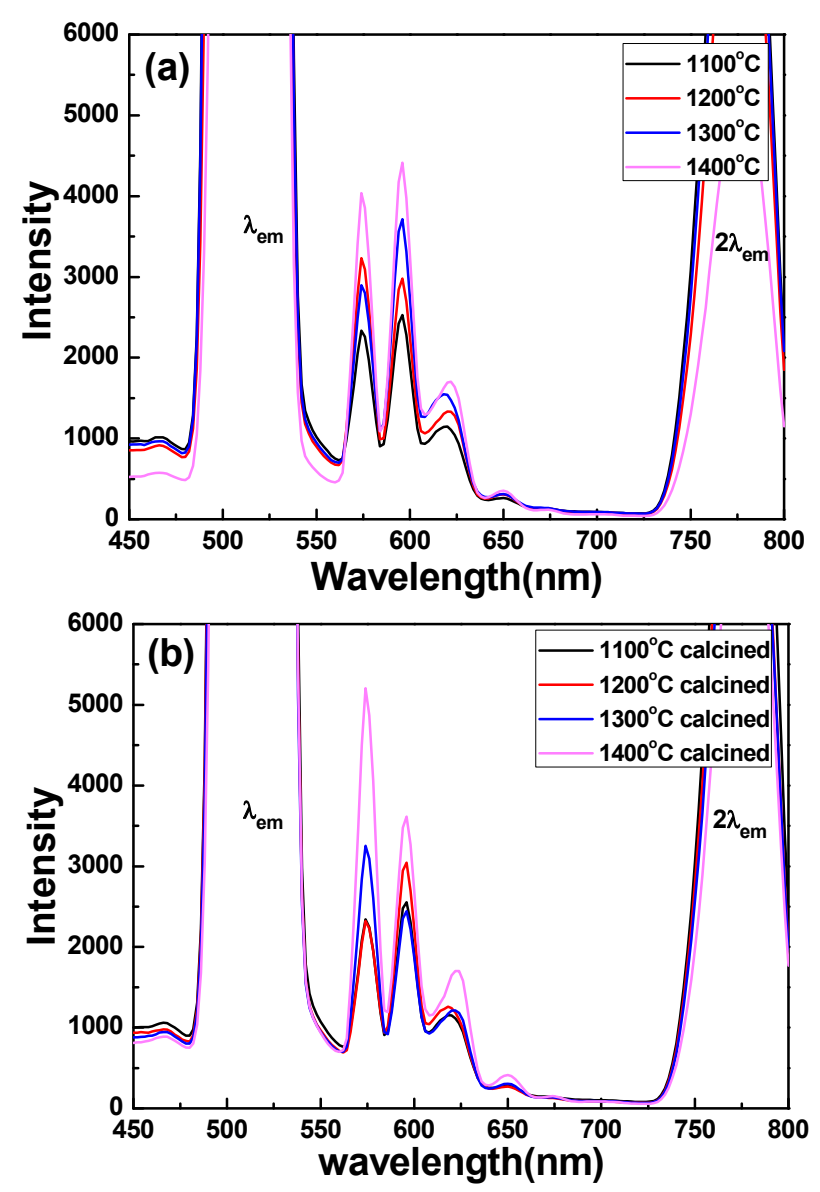

Figure 3. Emission spectrum of $\mathrm{BaZrO}_{3}: \mathrm{Eu}_{0.025}$ powders in the light wavelength of $450-800 \mathrm{~nm}$ as a function of heating process and heating temperature. (a) One-step Eu-BZO powders and (b) two-step Eu-BZO powders, respectively. ( $\lambda_{\mathrm{em}}$ : main peak of excitation spectra.) 
As Figure 4a,b show, no matter how the one-step Eu-BZO powders or the two-step Eu-BZO powders were measured, the splitting at the peak of ${ }^{5} \mathrm{D}_{0}-{ }^{7} \mathrm{~F}_{2}(616,623 \mathrm{~nm})$ was not observed in the one-step Eu-BZO powders or the two-step Eu-BZO powders. Also, the ${ }^{5} \mathrm{D}_{0}{ }^{7} \mathrm{~F}_{4}(673,696$, and $704 \mathrm{~nm})$ peak was not observed in Figure $4 \mathrm{a}, \mathrm{b}$. The results in Figure 4 also show that with the temperature changing from $1200{ }^{\circ} \mathrm{C}$ to $1300{ }^{\circ} \mathrm{C}$, the emission peak had large variation. For one-step Eu-BZO powders, as the heating temperature was changed from $1200^{\circ} \mathrm{C}$ to $1300^{\circ} \mathrm{C}$, the emission peak with the maximum intensity would change from the transition of ${ }^{5} \mathrm{D}_{0}{ }^{7} \mathrm{~F}_{0}$ to that of ${ }^{5} \mathrm{D}_{0}{ }^{7} \mathrm{~F}_{1}$. For two-step Eu-BZO powders, as the heating temperature was changed from $1200^{\circ} \mathrm{C}$ to $1300{ }^{\circ} \mathrm{C}$, the emission peak with the maximum intensity would change from the transition of ${ }^{5} \mathrm{D}_{0}-{ }^{7} \mathrm{~F}_{1}$ to that of ${ }^{5} \mathrm{D}_{0}-{ }^{7} \mathrm{~F}_{0}$.
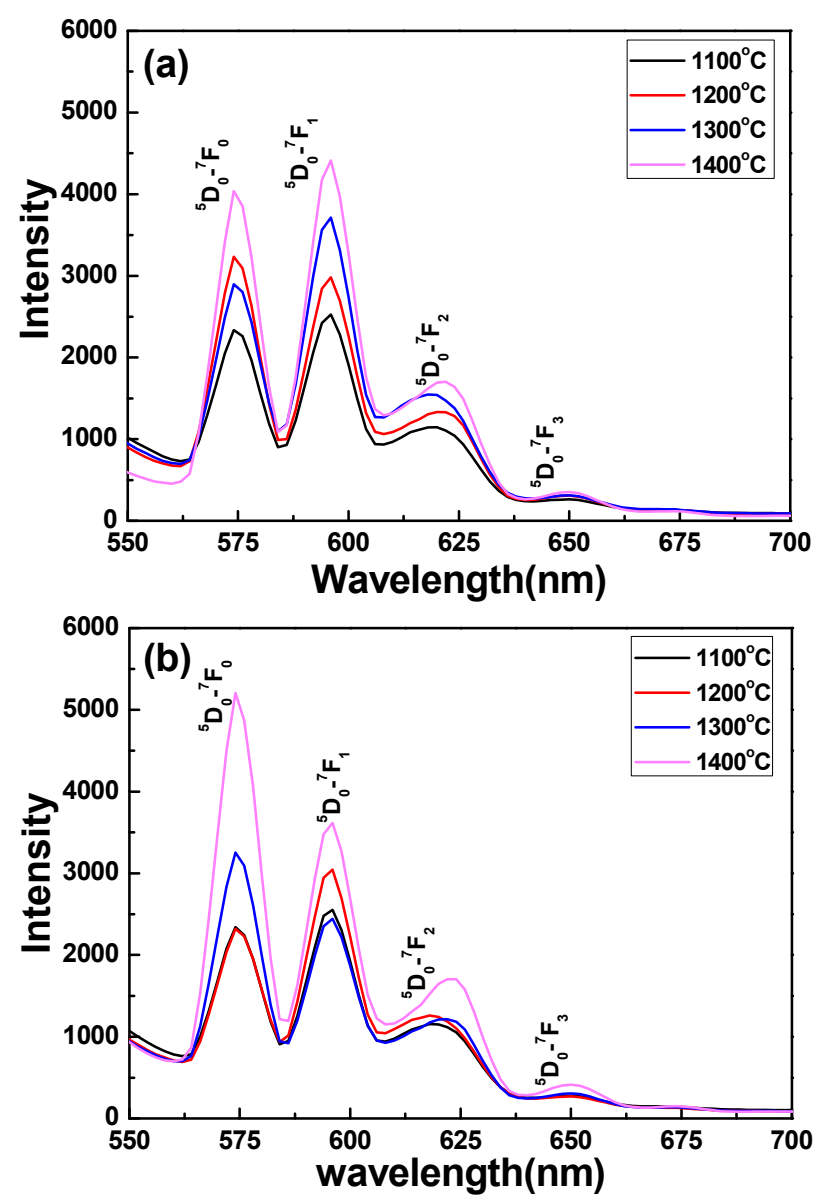

Figure 4. Emission spectrum of $\mathrm{BaZrO}_{3}: \mathrm{Eu}_{0.025}$ powders in the light wavelength of $550-700 \mathrm{~nm}$ as a function of heating process and heating temperature. (a) One-step Eu-BZO powders and (b) Two-step Eu-BZO powders, respectively.

The maximum emission intensities (PLmax) values of Eu-BZO powders in the transitions of the ${ }^{5} \mathrm{D}_{0}{ }^{7} \mathrm{~F}_{0}(576 \mathrm{~nm})$ and ${ }^{5} \mathrm{D}_{0}-{ }^{7} \mathrm{~F}_{1}(597 \mathrm{~nm})$ peaks are presented in Figure 5 as a function of heating process and temperature. Those results suggest again that the PL characteristics of Eu-BZO powders are strongly affected by the heating process and heating temperature. The emission intensity of the ${ }^{5} \mathrm{D}_{0}-{ }^{7} \mathrm{~F}_{1}(576 \mathrm{~nm})$ peak of one-step Eu-BZO powders and that of the ${ }^{5} \mathrm{D}_{0}-{ }^{7} \mathrm{~F}_{0}(597 \mathrm{~nm})$ peak of two-step Eu-BZO powders increased with the rising heating temperature, and the variations in the ${ }^{5} \mathrm{D}_{0}-{ }^{7} \mathrm{~F}_{0}$ peak of one-step Eu-BZO powders and in the ${ }^{5} \mathrm{D}_{0}-{ }^{7} \mathrm{~F}_{1}$ peak of two-step Eu-BZO powders had no apparent trend with the rising heating temperature. Thus, the maximum PLmax of all $\mathrm{BaZrO}_{3}: \mathrm{Eu}_{0.025}$ phosphors occurs for particles heated at $1400{ }^{\circ} \mathrm{C}$. Based on our SEM observations, we think this is the result of the Eu-BZO particle sizes increasing with rising heating temperature. 


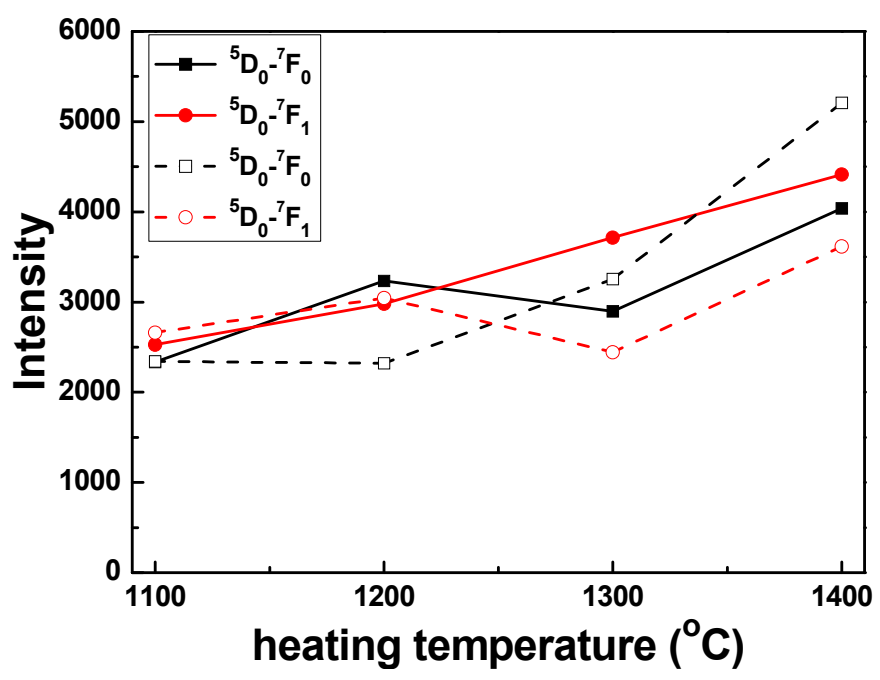

Figure 5. Emission intensity of $\mathrm{BaZrO}_{3}: \mathrm{Eu}_{0.025}$ phosphors as a function of heating process and heating temperature. Solid-line: one-step Eu-BZO powders, dashed-line: two-step Eu-BZO powders.

Figure 6 shows the emission photographs of heated Eu-BZO powders heated with different processes and temperatures. Those photographs prove that Eu-BZO phosphors with very bright emission intensity can easily be obtained by heating oxide precursors. Yu et al. found that $\mathrm{Eu}^{3+}$-doped $\mathrm{LiBaLaTeO}_{6}, \mathrm{NaBaLaTeO}_{6}$, and $\mathrm{LiBaBiTeO}_{6}$ show the dominant transition of ${ }^{5} \mathrm{D}_{0} \rightarrow{ }^{7} \mathrm{~F}_{2}$ with a pure red luminescence color and $\mathrm{Eu}^{3+}$-doped $\mathrm{NaCaBiTeO}_{6}$ presents the dominant reddish-orange emission from the transition of ${ }^{5} \mathrm{D}_{0} \rightarrow{ }^{7} \mathrm{~F}_{1}$ [16]. Those results suggest that the different $\mathrm{Eu}^{3+}$ ion transitions will happen. For one-step Eu-BZO powders, even the transition ${ }^{5} \mathrm{D}_{0} \rightarrow{ }^{7} \mathrm{~F}_{1}$ dominated the emission as the heating temperature was equal to and higher than $130{ }^{\circ} \mathrm{C}$; however, they all presented the reddish-orange emission, as Figure 6a shows. For two-step Eu-BZO powders, the domination transition changed from ${ }^{5} \mathrm{D}_{0} \rightarrow{ }^{7} \mathrm{~F}_{1}$ to ${ }^{5} \mathrm{D}_{0} \rightarrow{ }^{7} \mathrm{~F}_{0}$ as the heating temperature increased from $1100{ }^{\circ} \mathrm{C}$ to $1400{ }^{\circ} \mathrm{C}$; also, the emission changed from the reddish-orange color to orange, as Figure 6a-c show.
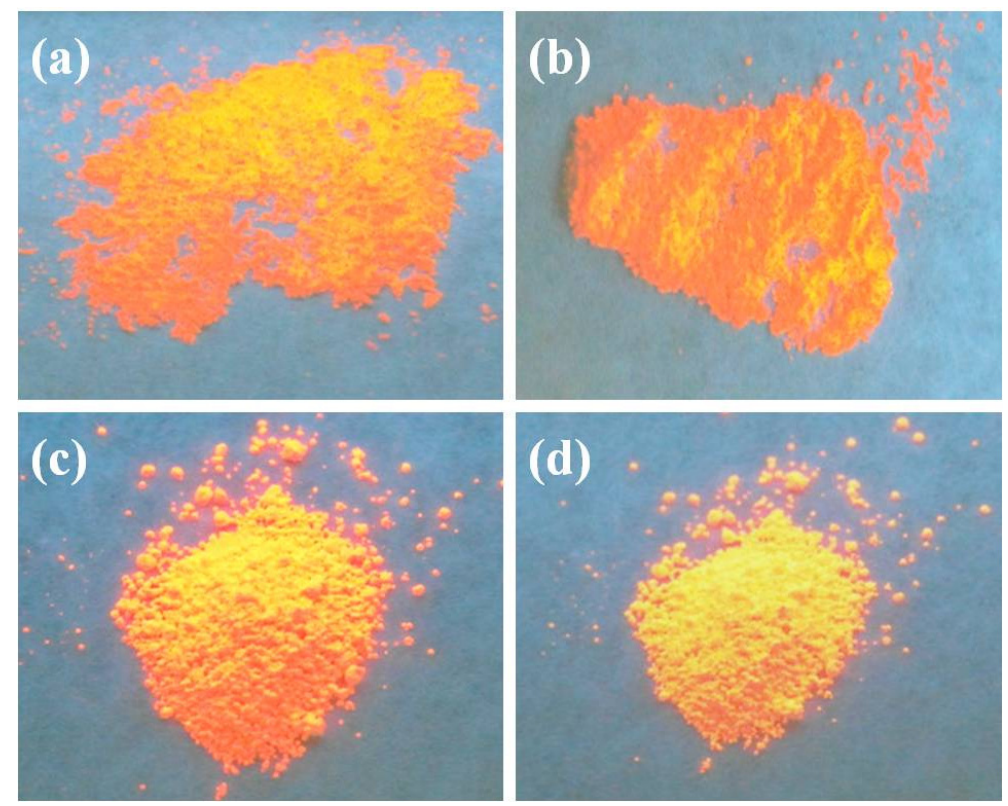

Figure 6. Photographs for the light emissions of heated Eu-BZO phosphors. (a) One-step Eu-BZO powder heated at $1300{ }^{\circ} \mathrm{C}$ and two-step Eu-BZO powders heated at (b) $1100{ }^{\circ} \mathrm{C}$, (c) $1200{ }^{\circ} \mathrm{C}$, and (d) $1400^{\circ} \mathrm{C}$, respectively. 
Phosphor materials are known for their use in radar screens and glow-in-the-dark toys, whereas fluorescent materials are common in cathode ray tubes (CRT) and plasma video display screens, sensors, and white LEDs. The activators have the effect of prolonging the emission time (afterglow) and some other materials, such as nickel, can be used to quench the emitting intensity and shorten the decay time of the phosphor emission characteristics. The intensity decay of the PL process can be expressed in the following functional form:

$$
I_{\mathrm{em}}=I_{0} \exp (-t / \tau)
$$

where the lifetime $\tau$ refers to the time required for the intensity to drop to $I_{0} / \mathrm{e}, I_{0}$ is the initial intensity, and $I_{\mathrm{em}}$ is the intensity at time $t$. Yu et al. also found that $\mathrm{Eu}^{3+}$-doped $\mathrm{LiBaLaTeO}_{6}, \mathrm{NaBaLaTeO}_{6}$, and $\mathrm{LiBaBiTeO}_{6}$ show a fast decay and $\mathrm{Eu}^{3+}$-doped $\mathrm{NaCaBiTeO}_{6}$ presents a longer luminescence lifetime [16]. As Figure 7 shows, the one-step Eu-BZO phosphors exhibited decay lifetimes extending from $2.52 \mathrm{~ms}$ to $3.98 \mathrm{~ms}$ and the two-step Eu-BZO phosphors exhibited decay lifetimes extending from $3.78 \mathrm{~ms}$ to $6.02 \mathrm{~ms}$. As we know in $\mathrm{Zn}_{2} \mathrm{SiO}_{4}-\mathrm{MnO}_{2}$ phosphors, if too much $\mathrm{MnO}_{2}$ dopant is added, a concentration quenching effect occurs, with resulting degeneration of the emission intensity and decay time $[20,21]$. Tzou et al. also found that as the $\mathrm{Mn}^{+2}$ dopant concentration and the heating temperature increase, the chance for $\mathrm{MnO}_{2}$ to substitute for $\mathrm{ZnO}$ increases and the concentration of $\mathrm{Mn}^{+2}$ ions increases. Energy transfer between $\mathrm{Mn}^{+2}$ and $\mathrm{Mn}^{+2}$ ions is expected to happen, which will take the excitation energy too far from the absorption location [21].

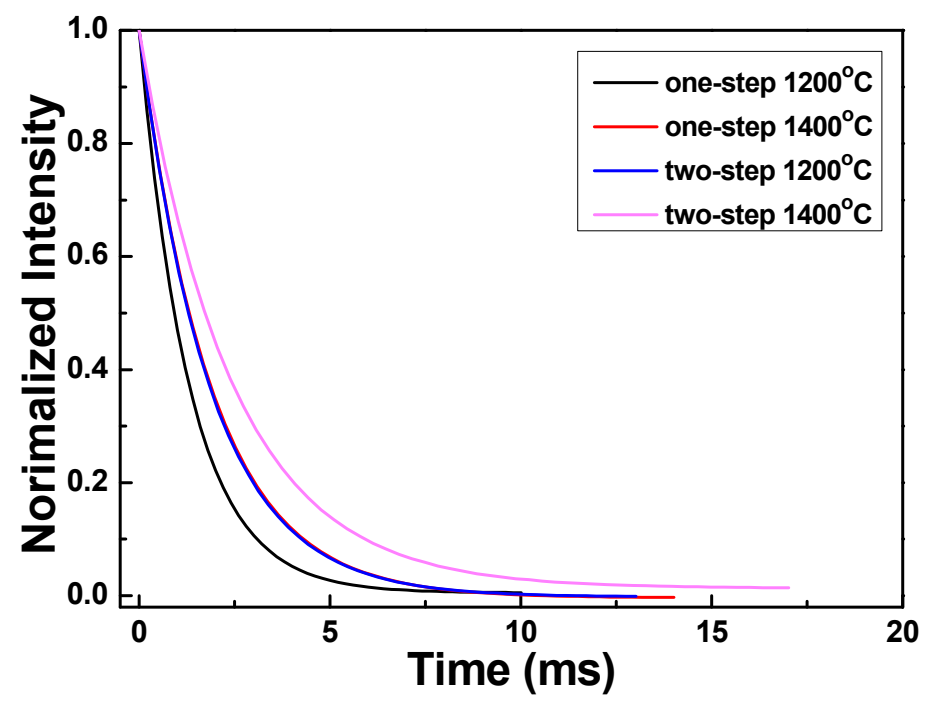

Figure 7. Decay time of $\mathrm{BaZrO}_{3}: \mathrm{Eu}_{0.025}$ powders as a function of heating process and heating temperature.

Equation (1) is most commonly used to describe the lifetime of phosphor materials with exponential decay and any one of the decay constant, mean lifetime, or half-life is sufficient to characterize the decay. It is known that the presence of impurities or crystal defects in semiconductors determines the lifetime of carriers, because a modified electronic structure within the crystal will give rise to defect levels, or energy levels that do not lie near the edge of the band gap. The Eu-BZO powders are prepared by using the solid-state reaction process and they are in the dispersed powder form rather than in the crystalline form. As such, it is hard to find the defect energy levels quantitatively. The $\mathrm{Eu}_{2} \mathrm{O}_{3}\left(\mathrm{Eu}^{3+}\right)$ ions are used to substitute the sites of $\mathrm{Zru}^{4+}$, and we have shown that the four dominant emission bands in the Eu-BZO powders are ${ }^{5} \mathrm{D}_{0}-{ }^{7} \mathrm{~F}_{0},{ }^{5} \mathrm{D}_{0}-{ }^{7} \mathrm{~F}_{1},{ }^{5} \mathrm{D}_{0}-{ }^{7} \mathrm{~F}_{2},{ }^{5} \mathrm{D}_{0}-{ }^{7} \mathrm{~F}_{3}$, respectively. A quantity may decay via two or more different processes simultaneously. In general, these processes are often called decay modes or decay routes and they have different probabilities of occurring, and, thus, occur at different rates with different half-lives, in parallel. For that we believe the decay time 
of Eu-BZO powders will be dependent on the variations from the excited state to the four domain emission bands. Thus, in the case of Eu-BZO powders, the total decay rate of quantity $N$ is given by the sum of the four decay modes:

$$
-\mathrm{d} N(t) / \mathrm{d} t=N_{1} / \tau_{1}+N_{2} / \tau_{2}+N_{3} / \tau_{3}+N_{4} / \tau_{4}
$$

If $N_{1}=N_{2}=N_{3}=N_{4}=1 / 4 N$, as Figure 8a shows, then Equation (2) will be changed as:

$$
-\mathrm{d} N(t) / \mathrm{d} t=N_{1} / \tau_{1}+N_{2} / \tau_{2}+N_{3} / \tau_{3}+N_{4} / \tau_{4}=1 / 4 N\left(1 / \tau_{1}+1 / \tau_{2}+1 / \tau_{3}+1 / \tau_{4}\right)
$$

If $1 / \tau_{1}=1 / \tau_{2}=1 / \tau_{3}=1 / \tau_{4}=1 / \tau$, as Figure $8 \mathrm{~b}$ shows, then Equation (2) will be changed as:

$$
-\mathrm{d} N(t) / \mathrm{d} t=N_{1} / \tau_{1}+N_{2} / \tau_{2}+N_{3} / \tau_{3}+N_{4} / \tau_{4}=\left(N_{1}+N_{2}+N_{3}+N_{4}\right) / \tau
$$

From Equations (2)-(4), we know the quantity and the half-life of $\mathrm{Eu}^{3+}$ ions in each transition mode will affect the lifetime of the Eu-BZO powders. However, the $N_{i}$ and $\tau_{i}(I=1,2,3$, and 4$)$ values are not the same values and it is very complicated to find the real solutions for the $\tau$ value Equations (2)-(4). From the results in Figure 4, the emissions of the $\mathrm{Eu}^{3+}$ ions corresponding to the ${ }^{5} \mathrm{D}_{0}{ }^{-}{ }^{7} \mathrm{~F}_{2}$ and ${ }^{5} \mathrm{D}_{0}-{ }^{7} \mathrm{~F}_{3}$ transitions have a weaker intensity and we suppose the two transitions have less effect on the decay time. The emissions of the Eu ${ }^{3+}$ ions corresponding to the ${ }^{5} \mathrm{D}_{0}{ }^{-}{ }^{7} \mathrm{~F}_{0}$ and ${ }^{5} \mathrm{D}_{0}{ }^{-}{ }^{7} \mathrm{~F}_{1}$ transitions are believed to dominate the lifetime. The main transition mode changes from the ${ }^{5} \mathrm{D}_{0}-{ }^{7} \mathrm{~F}_{1}$ to ${ }^{5} \mathrm{D}_{0}{ }^{-}{ }^{7} \mathrm{~F}_{0}$ and the maximum PL intensity (or the quantity $N$ ) increases as the two-step heating process and higher heating temperature are used. We believe that is the reason for the increase of the lifetime of the Eu-BZO powders.

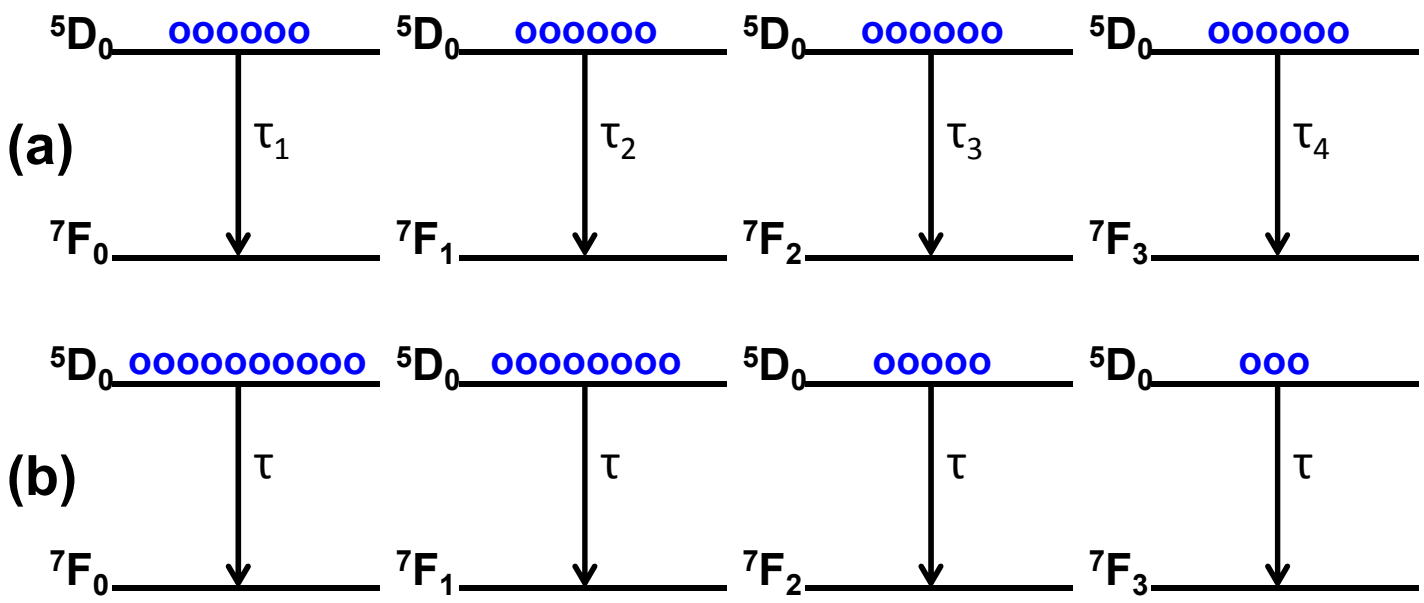

Figure 8. Diagrams for the decay rates of $\mathrm{BaZrO}_{3}: \mathrm{Eu}_{0.025}$ phosphors. (a) With same quantity $N$ and different decay time $\tau_{i} ;(\mathbf{b})$ With different quantity $N_{i}$ and same decay time $\tau$.

\section{Conclusions}

This study examined the $\mathrm{BaZrO}_{3}: \mathrm{Eu}_{0.025}$ phosphors prepared by the solid-state reaction method and $\mathrm{BaCO}_{3}+\mathrm{ZrO}_{2}+0.0125 \mathrm{Eu}_{2} \mathrm{O}_{3}$ precursors to investigate their photoluminescence properties. From the $\mathrm{XRD}$ patterns, as the same heating temperature was used, the diffraction intensity of the (110) peak of the two-step Eu-BZO powders was larger than that of the one-step Eu-BZO powders. The FWHM values of the (002) diffraction peak of the two-step Eu-BZO powders was smaller than that of the one-step Eu-BZO powders. The emission spectrum of the Eu-BZO powders consisted of sharp peaks of two strong bands corresponding to the ${ }^{5} \mathrm{D}_{0}-{ }^{7} \mathrm{~F}_{0}(574 \mathrm{~nm})$ and ${ }^{5} \mathrm{D}_{0}-{ }^{7} \mathrm{~F}_{1}(596 \mathrm{~nm})$ transitions of $\mathrm{Eu}^{3+}$ ions, and of two weak bands corresponding to the ${ }^{5} \mathrm{D}_{0}{ }^{-}{ }^{7} \mathrm{~F}_{2}(620 \mathrm{~nm})$ and ${ }^{5} \mathrm{D}_{0}{ }^{-}{ }^{7} \mathrm{~F}_{3}(650 \mathrm{~nm})$ 
transitions of $\mathrm{Eu}^{3+}$ ions, respectively. The one-step the two-step Eu-BZO phosphors exhibited decay lifetimes extending from $2.52 \mathrm{~ms}$ to $3.98 \mathrm{~ms}$ and from $3.78 \mathrm{~ms}$ to $6.02 \mathrm{~ms}$, respectively. As the heating temperature was equal to and higher than $1300{ }^{\circ} \mathrm{C}$, the one-step Eu-BZO phosphors presented a reddish-orange emission. For two-step Eu-BZO powders, as the heating temperature increased from $1100{ }^{\circ} \mathrm{C}$ to $1400{ }^{\circ} \mathrm{C}$, the dominant transition changed from ${ }^{5} \mathrm{D}_{0} \rightarrow{ }^{7} \mathrm{~F}_{1}$ to ${ }^{5} \mathrm{D}_{0} \rightarrow{ }^{7} \mathrm{~F}_{0}$ and the emission changed from a reddish-orange to orange color. In this study, we prove that Eu-BZO phosphors with very bright emission intensity can easily be obtained by heating oxide precursors.

Acknowledgments: The authors acknowledge financial supports of MOST 104-2221-E-390-013-MY2 and MOST 104-2622-E-390-004-CC3.

Author Contributions: Jing Liu and Yi-Tang Chiu helped proceeding the experimental processes, measurements, and data analysis; Chao-Ming Hsu helped proceeding the experimental processes and measurements; Kun-Neng Chen and Cheng-Fu Yang organized the paper and encouraged the paper writing.

Conflicts of Interest: The authors declare no conflict of interest.

\section{References}

1. Naidu, S.A.; Boudin, S.; Varadaraju, U.V.; Raveau, B. Influence of structural distortions upon photoluminescence properties of $\mathrm{Eu}^{3+}$ and $\mathrm{Tb}^{3+}$ activated $\mathrm{Na}_{3} \operatorname{Ln}\left(\mathrm{BO}_{3}\right)_{2}(\mathrm{Ln}=\mathrm{Y}, \mathrm{Gd})$ borates. J. Solid State Chem. 2012, 190, 186-190. [CrossRef]

2. Zhang, Y.; Huang, Y.; Yang, M.; Guo, N.; Qiao, H.; Jia, Y.; You, H.J. Synthesis and tunable luminescence properties of monodispersed sphere-like $\mathrm{CaWO}_{4}$ and $\mathrm{CaWO}_{4}: \mathrm{Mo} / \mathrm{Eu}, \mathrm{Tb}$. J. Lumin. 2012, 132, 362-367. [CrossRef]

3. Xia, Z.G.; Liao, L.B.; Zhang, Z.Z.; Wang, Y.F. Combustion synthesis and luminescence properties of yellow-emitting phosphors $\mathrm{Ca}_{2} \mathrm{BO}_{3} \mathrm{Cl}: \mathrm{Eu}^{2+}$. Mater. Res. Bull. 2012, 47, 405-408. [CrossRef]

4. Xia, Z.G.; Du, H.Y.; Sun, J.Y.; Chen, D.M.; Wang, X.F. A novel blue-emitting $\mathrm{Ca}_{2} \mathrm{~B}_{5} \mathrm{O}_{9} \mathrm{Br}$ Eu ${ }^{2+}$ phosphor prepared by a microwave calcination route. Mater. Chem. Phys. 2010, 119, 7-10. [CrossRef]

5. Murthy, K.V.R.; Sai Prasad, A.S.; Ramaligeshwar Rao, M. Luminescence characteristics of Eu and Tb doped $\mathrm{YGdBO}_{3}$ phosphor. Phys. Procedia 2012, 29, 70-75. [CrossRef]

6. Macario, L.R.; Moreira, M.L.; Andrés, J.; Longo, E. An efficient microwave-assisted hydrothermal synthesis of $\mathrm{BaZrO}_{3}$ microcrystals: Growth mechanism and photoluminescence emissions. CrystEngComm 2010, 12, 3612-3619. [CrossRef]

7. Cavalcante, L.S.; Sczancoski, J.C.; Longo, V.M.; de Vicente, F.S.; Sambrano, J.R.; de Figueiredo, A.T.; Dalmaschio, C.J.; Li, M.S.; Varela, J.A.; Longo, E. Intense violet-blue photoluminescence in $\mathrm{BaZrO}_{3}$ powders: A theoretical and experimental investigation of structural order-disorder. Opt. Commun. 2008, 281, 3715-3720. [CrossRef]

8. Yuan, Y.; Zhang, X.; Liu, L.; Jiang, X.; Lv, J.; Li, Z.; Zou, Z. Synthesis and photocatalytic characterization of a new photocatalyst $\mathrm{BaZrO}_{3}$. Int. Hydrog. Energy 2008, 33, 5941-5946. [CrossRef]

9. Borja-Urby, R.; Diaz-Torres, L.A.; Salas, P.; Vega-Gonzalez, M.; Angeles-Chavez, C. Blue and red emission in wide band gap $\mathrm{BaZrO}_{3}: \mathrm{Yb}^{3+}, \mathrm{Tm}^{3+}$. Mater. Sci. Eng.: B 2010, 174, 169-173. [CrossRef]

10. Zhang, H.; Fu, X.; Niu, S.; Xin, Q. Synthesis and photoluminescence properties of $\mathrm{Eu}^{3+}-$ doped $A Z \mathrm{ZrO}_{3}$ ( $A=\mathrm{Ca}, \mathrm{Sr}, \mathrm{Ba})$ perovskite. J. Alloys Compd. 2008, 459, 103-106. [CrossRef]

11. Sun, D.; Li, D.; Zhu, Z.; Xiao, J.; Tao, Z.; Liu, W. Photoluminescence properties of europium and titanium co-doped $\mathrm{BaZrO}_{3}$ phosphors powders synthesized by the solid-state reaction method. Opt. Mater. 2012, 34, 1890-1896. [CrossRef]

12. Mari, B.; Singh, K.C.; Sahal, M.; Khatkar, S.P.; Taxak, V.B.; Kumar, M. Preparation and luminescence properties of $\mathrm{Tb}^{3+}$ doped $\mathrm{ZrO}_{2}$ and $\mathrm{BaZrO}_{3}$ phosphors. J. Lumin. 2010, 130, 2128-2132. [CrossRef]

13. Yang, H.; Liu, Q.; Wei, Q.; Zhou, Z.; Wan, J.; Liu, G. Eu-doped $\beta$-SiAlON phosphors: Template-assistant low temperature synthesis, dual band emission, and high-thermal stability. J. Am. Ceram. Soc. 2014, 97, 3164-3169. [CrossRef]

14. Zambare, A.P.; Murthy, K.V.R. Photoluminescence studies of Eu doped Yttrium based phosphors. Arch. Phys. Res. 2011, 2, 46-50. 
15. Jang, B.Y.; Park, J.S.; Kim, J.S.; Han, S.O.; Kim, H.S.; Ahn, Y.S.; Yoo, S.J. Structures and luminescence properties of $\mathrm{Eu}^{2+}$-doped $\alpha$-sialon phosphors for UV-LED. J. Electroceram. 2009, 23, 312-316. [CrossRef]

16. Yu, R.; Wang, C.; Chen, J.; Wu, Y.; Li, H.; Ma, H. Photoluminescence characteristics of Eu ${ }^{3+}$-doped double-perovskite phosphors. J. Solid State Sci. Technol. 2014, 3, R33-R37. [CrossRef]

17. Kanie, K.; Seino, Y.; Matsubara, M.; Nakaya, M.; Muramatsua, A. Hydrothermal synthesis of $\mathrm{BaZrO}_{3}$ fine particles controlled in size and shape and fluorescence behavior by europium doping. New J. Chem. 2014, 38, 3548-3555. [CrossRef]

18. Wei, Y.F.; Chung, H.H.; Yang, C.F.; Chen, K.H.; Diao, C.C.; Kao, C.H. The influence of different fabrication processes on characteristics of excess $\mathrm{Bi}_{2} \mathrm{O}_{3}$-doped $0.95\left(\mathrm{Na}_{0.5} \mathrm{Bi}_{0.5}\right) \mathrm{TiO}_{3}-0.05 \mathrm{BaTiO}_{3}$ ceramics. J. Phys. Chem. Solids 2008, 69, 934-940. [CrossRef]

19. Liu, X.; Wang, X. Preparation and luminescence properties of $\mathrm{BaZrO}_{3}$ :Eu phosphor powders. Opt. Mater. 2007, 30, 626-629. [CrossRef]

20. Manavbasi, A.; LaCombe, J.C. Synthesis of pure $\mathrm{Zn}_{2} \mathrm{SiO}_{4}: \mathrm{Mn}$ green phosphors by simple PVA-metal complex route. J. Mater. Sci. 2007, 42, 252-258. [CrossRef]

21. Tzou, W.C.; Diao, C.C.; Yang, C.F.; Kuo, C.G.; Huang, C.J. Developing the properties of new blue phosphors: $\mathrm{TiO}_{2}$-doped $\mathrm{Zn}_{2} \mathrm{SiO}_{4}$. Ceram. Int. 2011, 37, 1341-1344. [CrossRef]

(C) 2016 by the authors; licensee MDPI, Basel, Switzerland. This article is an open access article distributed under the terms and conditions of the Creative Commons by Attribution (CC-BY) license (http://creativecommons.org/licenses/by/4.0/). 